\title{
Modulating effects of plasma containing anti-malarial antibodies on in vitro anti-malarial drug susceptibility in Plasmodium falciparum
}

\author{
Preeyaporn Monatrakul', Mathirut Mungthin², Arjen M Dondorp ${ }^{1,3}$, Srivicha Krudsood ${ }^{1,4}$, \\ Rachanee Udomsangpetch ${ }^{5}$, Polrat Wilairatana ${ }^{1,4}$, Nicholas J White ${ }^{1,3}$, Kesinee Chotivanich ${ }^{1 *}$
}

\begin{abstract}
Background: The efficacy of anti-malarial drugs is determined by the level of parasite susceptibility, anti-malarial drug bioavailability and pharmacokinetics, and host factors including immunity. Host immunity improves the in vivo therapeutic efficacy of anti-malarial drugs, but the mechanism and magnitude of this effect has not been characterized. This study characterized the effects of 'immune' plasma to Plasmodium falciparumon the in vitro susceptibility of $P$. falciparum to anti-malarial drugs.
\end{abstract}

Methods: Titres of antibodies against blood stage antigens (mainly the ring-infected erythrocyte surface antigen [RESA]) were measured in plasma samples obtained from Thai patients with acute falciparum malaria. 'Immune' plasma was selected and its effects on in vitro parasite growth and multiplication of the Thai $P$. falciparum laboratory strain TM267 were assessed by light microscopy. The in vitro susceptibility to quinine and artesunate was then determined in the presence and absence of 'immune' plasma using the ${ }^{3} \mathrm{H}$-hypoxanthine uptake inhibition method. Drug susceptibility was expressed as the concentrations causing 50\% and $90 \%$ inhibition $\left(I C_{50}\right.$ and $\left.I C_{90}\right)$, of ${ }^{3} \mathrm{H}$-hypoxanthine uptake.

Results: Incubation with 'immune' plasma reduced parasite maturation and decreased parasite multiplication in a dose dependent manner. ${ }^{3} \mathrm{H}$-hypoxanthine incorporation after incubation with 'immune' plasma was decreased significantly compared to controls (median [range]; 181.5 [0 to 3,269] cpm versus 1,222.5 [388 to 5,932] cpm) ( $p=0.001$ ). As a result 'immune' plasma reduced apparent susceptibility to quinine substantially; median (range) $I_{50} 6.4$ (0.5 to 23.8 ) ng/ml versus $221.5(174.4$ to 250.4$) \mathrm{ng} / \mathrm{ml}(p=0.02)$, and also had a borderline effect on artesunate susceptibility; $I C_{50} 0.2$ $(0.02$ to 0.3$) \mathrm{ng} / \mathrm{ml}$ versus $0.8(0.2$ to 2.3$) \mathrm{ng} / \mathrm{ml}(p=0.08)$. Effects were greatest at low concentrations, changing the shape of the concentration-effect relationship. $I C_{90}$ values were not significantly affected; median (range) $I C_{90} 448.0$ ( 65 to $>500) \mathrm{ng} / \mathrm{ml}$ versus 368.8 (261 to 501$) \mathrm{ng} / \mathrm{ml}$ for quinine $(p>0.05)$ and $17.0(0.1$ to 29.5$) \mathrm{ng} / \mathrm{ml}$ versus 7.6 (2.3 to 19.5$) \mathrm{ng} / \mathrm{ml}$ for artesunate $(p=0.4)$.

Conclusions: 'Immune' plasma containing anti-malarial antibodies inhibits parasite development and multiplication and increases apparent in vitro anti-malarial drug susceptibility of $P$. falciparum. The $I C_{90}$ was much less affected than the $I_{50}$ measurement.

\section{Background}

Falciparum malaria remains the most important parasite infection in the tropical world. Development of antimalarial drug resistance is a major threat for malaria

\footnotetext{
* Correspondence: nok@tropmedres.ac

'Department of Clinical Tropical Medicine, Faculty of Tropical Medicine,

Mahidol University, 420/6 Rajvithi, Bangkok, Thailand 10400

Full list of author information is available at the end of the article
}

control. Early signs of low-grade resistance can be obscured by anti-malarial immunity. The positive contribution of host immunity to the therapeutic response to anti-malarial drugs has been recognized for nearly a century [1]. In endemic areas, protective immunity is acquired and maintained with repeated exposure to Plasmodium falciparum and is an important factor determining therapeutic outcome following anti-malarial 
drug treatment [2,2-5]. Failing drugs can appear effective if tested in semi-immune adults, whilst cure rates in children from the same area are unacceptable [4]. The host defence against malaria, which includes preerythrocytic immunity, blood stage immune responses and augmented splenic clearance function, is still poorly characterized. Antibody clearly plays a role; for example increased levels of anti-MSP1 19 IgG1 were associated with improved efficacy of sulphadoxine-pyrimethamine in Gabonese children [5] but the precise contributions of this and other antibodies to drug efficacy were not quantitated. Immunity is associated with both augmentation of parasite clearance responses and increased cure rates. An increase in parasite clearance times after treatment with artesunate-mefloquine combination therapy on the Thai-Myanmar border after 2002 coincided with a sharp reduction in malaria transmission in the area could be explained by lower immunity in this population [6]. The quantitative contribution of host immunity to drug efficacy is difficult to assess, and there are few studies addressing this ex vivo. The current study quantitated the effects of 'immune' plasma containing antimalarial antibodies on parasite growth and susceptibility of $P$. falciparum to quinine and artesunate.

\section{Methods}

\section{Malaria parasites}

Plasmodium falciparum Thai laboratory strain TM267, was cultured in malaria culture medium (MCM) supplemented with 0.5\% Albumax II (Gibco, New Zealand) as previously described [7]. Parasites were synchronized to ring stage through treatment with 5\% D-sorbitol [8] just prior to the experiments.

\section{Selection of 'immune' plasma}

Plasma was obtained from patients with acute P. falciparum malaria taking part in clinical studies performed at the Hospital for Tropical Diseases in Bangkok, Thailand approved by the Ethics committee of the Faculty of Tropical Medicine, Mahidol University. Patients who had no history of anti-malarial drug treatment before admission were screened for previous treatment with quinine and mefloquine using dipstick. Plasma was assessed for the presence of antibodies against blood stage antigens (mainly ring-infected erythrocyte surface antigen [RESA]) by an immunofluorescence assay (IFA), as described previously [9]. In brief, $10 \mu \mathrm{l}$ of plasma $(1: 50 \mathrm{v} / \mathrm{v}$ in phosphate buffered saline [PBS]) was applied on an antigen-coated slide, incubated at room temperature for 30 minutes, and then washed twice with PBS. Five microlitres of rabbit anti-human IgG conjugated to fluorescein isothiocyanate (FITC; DAKO, Denmark) (1:50 v/v in PBS) was then added to each spot on the antigen-coated slide, incubated at room temperature for 30 minutes (protected from light), and then washed twice with PBS. The slides were counterstained and mounted with $10 \mu \mathrm{g} / \mathrm{ml}$ ethidium bromide (Sigma, USA) in 50\% glycerol (Sigma, USA), and then examined under a fluorescence microscope (Model BX60; Olympus, Japan). Plasma reacting positively showed as a coated green fluorescence on the surface of infected red blood cells. Plasma positive for blood stage antibodies at a titre 1:50 ( $/ \mathrm{v})$ was then further assessed at titres of 1:250 and $1: 1,250(\mathrm{v} / \mathrm{v})$. 'Immune' plasma was defined as plasma containing blood stage antibodies at titre greater than 1:50. Individual plasma $(\mathrm{N}=1)$ at a titre of 1:50 was used for the assessment of the effect on the parasite growth. Plasma at tires of 1:250 $(\mathrm{N}=2)$ and 1:1,250 ( $\mathrm{N}=1)$ were used for the assessment of the effects on the anti-malarial drug susceptibility. The plasma samples were then heated at $56^{\circ} \mathrm{C}$ for 30 minutes and then kept at $-20^{\circ} \mathrm{C}$ until used.

\section{Effects of 'immune' plasma containing anti-malarial antibodies on growth of Plasmodium falciparum}

Twenty-five microlitres of synchronized ring stage P. falciparum(TM267), at 1\% P. falciparum infected erythrocytes with $>80 \%$ ring stages were incubated with either $25 \mu \mathrm{l}$ 'immune' plasma containing anti-malarial antibodies or plasma from healthy subjects at concentrations of $2.5 \%, 5 \%, 10 \%, 20 \%$, and $40 \%$ (v/v in MCM) at $37^{\circ} \mathrm{C}$ for 48 hours. Parasites incubated with MCM supplemented with $0.5 \%$ Albumax II (without 'immune' plasma) were included as controls. Parasite growth and stage of development were assessed by microscopy [10]. Parasite multiplication was then assessed as the percentage of ring-infected red cells in all infected red blood cells after 48 hours incubation in the presence of 'immune' plasma containing anti-malarial antibodies relative to control (without 'immune' plasma). All experiments were repeated four times.

\section{Drug susceptibility assay}

Assessments of parasite growth and anti-malarial drug susceptibility of $P$. falciparum TM267 were assessed by an isotopic assay using tritium $\left[{ }^{3} \mathrm{H}\right]$-hypoxanthine as described previously [11]. In brief, $50 \mu \mathrm{l}$ of a $3 \%$ haematocrit red cell suspension containing $1 \%$ P. falciparum infected erythrocytes with $>80 \%$ in the ring stage of development, was incubated with quinine dihydrochloride (A.N.B. Laboratories Co., Ltd., Thailand) (range of concentrations: $7.80-500 \mathrm{ng} / \mathrm{ml}$ ) and artesunate (Guilin Pharmaceutical Co., Ltd., China) (range of concentrations: $0.16-10 \mathrm{ng} / \mathrm{ml}$ ), either in the absence or presence of $10 \%(\mathrm{v} / \mathrm{v})$ 'immune' plasma containing anti-malarial antibodies. Parasites were incubated at $37^{\circ} \mathrm{C}$ until development to the trophozoite stage. ${ }^{3} \mathrm{H}$-hypoxanthine 
$(25 \mu \mathrm{l}: 0.025 \mathrm{uCi} / \mu \mathrm{l})$ was then added to each well after which the plates were incubated at $37^{\circ} \mathrm{C}$ and $5 \% \mathrm{CO}_{2}$ for 24 hours until parasites reached the mature schizont stage, and then frozen at $-80^{\circ} \mathrm{C}$. After thawing of the sample, the lysed cells were transferred to a glass fibre filter (Wallac, Turku, Finland) using a cell harvester (Packard Instruments, Meriden, Conn.) and ${ }^{3} \mathrm{H}$-hypoxanthine uptake was measured by a scintillation counter (MicroBeta; Wallac Trilux). Four experiments were done in duplicate. The measure of drug susceptibility was the concentration of drug inhibiting ${ }^{3} \mathrm{H}$-hypoxanthine uptake by $50 \%$ and $90 \%$ relative to control ( $50 \%$ and $90 \%$ inhibitory concentrations; $\mathrm{IC}_{50}$ and $\left.\mathrm{IC}_{90}\right)$. The $\mathrm{IC}_{50}$ and the $\mathrm{IC}_{90}$ values were assessed by fitting a sigmoid dose response curve using WinNonlin software version 4.1 (Pharsight Corporation, CA).

\section{Statistical analyses}

Statistical analyses was performed using SPSS version 11.5 (SPSS Inc., Illinois, USA). The Mann-Whitney $\mathrm{U}$ test was used for comparing groups with nonnormally distributed data. A $p$-value $\leq 0.05$ was considered statistically significant.

\section{Results}

The effects of 'immune' plasma on the growth of Plasmodium falciparum

Seventy-eight plasma samples from uncomplicated malaria patients were screened for antibodies against $P$. falciparum ring stages antigens using the immunofluorescence assay (IFA). A total of 51 patients (65\%) had plasma containing blood stage antibodies assessed by IFA, of whom 31 (61\%) had a titre of 1:50, 17 (33\%) a titre of $1: 250$, and $3(6 \%)$ a titre of $1: 1,1250$. In the in vitro culture, control plasma from healthy subjects did not react with infected red blood cells. Parasites developed completely from ring to schizont stage over a 48 hour time period. The median (range) parasitaemia after schizogony was $1.6 \%$ (1.5-1.7), 1.5\% (1.4-1.6), 1.5\%
(1.4-1.7), $1.4 \%(1.3-1.4)$, and $1.2 \%(1.0-1.4)$ in the presence of $2.5 \%, 5 \%, 10 \%, 20 \%$, and $40 \%(\mathrm{v} / \mathrm{v})$ normal plasma, respectively (Table 1 ). Growth was significantly inhibited $(p \leq 0.05)$ by concentrations of normal plasma $\geq 20 \%$ but not by lower concentrations. Parasite growth was inhibited more after incubation with 'immune' plasma. In the presence of 'immune' plasma (titre of $1: 50)$ at $2.5 \%, 5 \%, 10 \%, 20 \%$, and $40 \%(\mathrm{v} / \mathrm{v})$, the corresponding parasitaemia was $1.7 \%(1.2-2.1), 1.4 \%(0.7-1.4)$, $1.1 \%$ (0.9-1.2), $1.1 \%(0.5-1.2)$, and $0.9 \%(0.7-1.2)$, respectively. The parasitaemia after incubation with $10 \%, 20 \%$, and $40 \%$ 'immune' plasma were all significantly reduced compared to control $(p<0.05)$ (Table 1). Thus, the median (range) number of ring infected red cells after schizogony was reduced by $8.2 \%(0-26.3), 40.3 \%$ (0-70.3), $74.5 \%$ (33.3-83.1), 80\% (57.1-100), and 93.9\% (75-100) in the presence of $2.5 \%, 5 \%, 10 \%, 20 \%$, and $40 \%$ 'immune' plasma, respectively ( $p$ for trend $=0.001$ ).

The absolute ${ }^{3} \mathrm{H}$-hypoxanthine uptake after incubation with $10 \%$ 'immune' plasma was markedly lower compared to control (median [range]; 181.5 [0-3,269] cpm versus $1,222.5$ [388-5,932] cpm; $p=0.001$ ) (Figure 1). Thus, 'immune' plasma inhibited parasite growth and the development from ring to schizont stages and also inhibited the multiplication of P. falciparum.

\section{Effects of 'immune' plasma on the in vitro measurement of anti-malarial drug susceptibility}

The susceptibility of $P$. falciparum to the anti-malarial drugs quinine and artesunate, either in the presence or absence of $10 \%$ 'immune' plasma is shown in Figure 2. In the presence of 'immune' plasma (titres of 1:250 and $1: 1,250)$, hypoxanthine uptake was markedly reduced at lower drug concentrations (Figure 3). The median (range) derived $\mathrm{IC}_{50}$ values for quinine in the presence and absence of 'immune' plasma were 6.4 (0.5-23.8) ng/ $\mathrm{ml}$ and $221.5(174.4-250.4) \mathrm{ng} / \mathrm{ml}$, respectively $(p=0.02)$. The corresponding median (range) derived $\mathrm{IC}_{90}$ values for quinine were not significantly different; 448.0

Table 1 Plasmodium falciparum parasitaemia in culture in the presence of plasma from healthy donors and 'immune' plasma

\begin{tabular}{|c|c|c|}
\hline \multirow[t]{2}{*}{ Plasma concentration } & \multicolumn{2}{|c|}{ Median (range) \% parasitaemia after 48 hours incubation * } \\
\hline & Normal plasma & 'Immune' plasma ** \\
\hline Control (MCM) & $1.7(1.5-2.6)$ & $1.7(1.4-2.3)$ \\
\hline $2.5 \%$ & $1.6(1.5-1.7)$ & $1.7(1.2-2.1)$ \\
\hline $5 \%$ & $1.5(1.4-1.6)$ & $1.4(0.7-1.4)$ \\
\hline $10 \%$ & $1.5(1.4-1.7)$ & $1.1(0.9-1.2)^{* * *}$ \\
\hline $20 \%$ & $1.4(1.3-1.4)^{* * *}$ & $1.1(0.5-1.2)^{* * *}$ \\
\hline $40 \%$ & $1.2(1-1.4) * * *$ & $0.9(0.7-1.2) * * *$ \\
\hline
\end{tabular}

\footnotetext{
*- The percentage of infected red blood cells counted per 1,000 red blood cells.

**- 'Immune' plasma (titre of 1:50).

***- Significant difference compared to control; $p \leq 0.05(\mathrm{~N}=4)$. MCM is malaria culture medium.
} 
${ }^{3} \mathrm{H}-$ hypoxanthine uptake (cpm)

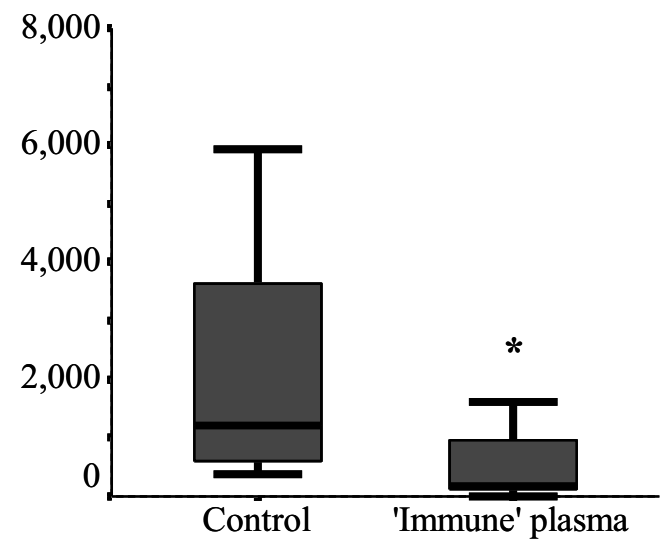

Figure 1 Plasma from acute malaria inhibits ${ }^{3} \mathrm{H}$-hypoxanthine uptake by Plasmodium falciparum. Parasites were incubated in malaria culture medium with 10\% (v/v) 'immune' plasma containing anti-malarial antibodies for 48 hours. Parasite uptake of

hypoxanthine (in counts per minute; cpm) is shown as the median values with $25^{\text {th }}$ and $75^{\text {th }}$ percentiles and ranges from 4 experiments in duplicate. Control parasites were incubated in culture medium with $10 \%$ plasma from healthy donors. ${ }^{*} p \leq 0.05$ (Mann-Whitney $U$ test).

(65->500) $\mathrm{ng} / \mathrm{ml}$ and 368.8 (261-501) $\mathrm{ng} / \mathrm{ml}$, respectively $(p>0.05)$. The median (range) derived $\mathrm{IC}_{50}$ values for artesunate in the presence and absence of 'immune' plasma were $0.2(0.02-0.3) \mathrm{ng} / \mathrm{ml}$ and $0.8(0.22-2.29) \mathrm{ng} /$ $\mathrm{ml}$, respectively $(p=0.08)$. The corresponding median (range) derived $\mathrm{IC}_{90}$ values for artesunate were not significantly different: $17.0(0.1-29.5) \mathrm{ng} / \mathrm{ml}$ and $7.6(2.3-19.5)$ $\mathrm{ng} / \mathrm{ml}$, respectively $(p=0.4)$.

\section{Discussion}

Assessing anti-malarial resistance in patients living in malaria endemic regions of the world is hampered by the presence of host immunity, which can act as an important confounder [1]. Early resistance can thus go unnoticed, because host immunity assists the drug in parasite clearance. Conversely, waning immunity in a population with a reduction in malaria transmission can cause a false impression of reduced drug efficacy. Exactly which immunological factors are important in enhancing anti-malarial drug efficacy remains unclear. The current study investigated the role of 'immune' plasma containing anti-malarial antibodies in an in vitro growth system and standard sensitivity drug assay. The study confirms earlier studies and the experience of malariologists conducting in vitro susceptibility testing that 'immune' plasma significantly inhibits the development of $P$. falciparum from the ring to schizont stage of development and also inhibits parasite multiplication. The mechanism of action of antibodies is not well understood. Antibodies are thought to reduce parasite multiplication through interference with merozoite invasion (e.g. through anti-MSP-1 [12] and anti-EBA-175 antibodies [13]) and with intraerythrocytic development [14] (e.g. through anti-RESA [15-18] and anti-PfEMP-1 antibodies [19]). How they impair growth is poorly understood. Anti-RESA antibodies have been shown previously to inhibit parasite growth [15-17] and multiplication [18] and they can be used as markers of the broader humoral immune response [20]. Anti-MSP-1 antibodies have been shown to prevent the processing of merozoite surface proteins [12] and anti-EBA-175 antibodies have been proposed to interfere with the recognition of erythrocyte ligands, both involved in the invasion process [13]. Antibodies to PfEMP-1 agglutinate infected RBCs, and through this mechanism are thought to inhibit merozoite invasion and parasite multiplication [19].

In addition to anti-malarial antibodies, plasma obtained from patients with an acute falciparum malaria infection also contains other factors which inhibit parasite growth. Acute phase proteins such as C-reactive protein, $\alpha 1$-acid glycoprotein, mannose-binding protein, and complement may affect the multiplication of $P$. falciparum. It has been proposed that $\alpha 1$-acid glycoprotein inhibits parasite multiplication by interfering with parasite-erythrocyte interactions during the invasion process [21]. C-reactive protein has been proposed to prevent the penetration of sporozoites into hepatocytes and to inhibit parasite replication during pre-erythrocytic development [22]. Mannose-binding protein (MBP) can initiate the lectin complement pathway eventually leading to cell lysis [23]. In the present study, inactivated plasma by heating at $56^{\circ} \mathrm{C}$ for 30 minutes was used in the experiments. Through this procedure proteins of the complement system lost their enzymatic activity [24] and therefore, complement factors and MBP were unlikely to have interfered with parasite development in the current study. The study also addressed the effects of nonspecific proteins in plasma from normal donors on parasite development. Normal plasma showed no effect in concentrations up to $10 \%(\mathrm{v} / \mathrm{v})$, but did inhibit parasite growth in higher concentrations of $20 \%$ and $40 \%(\mathrm{v} / \mathrm{v})$. For this reason, a $10 \%$ plasma concentration (v/v) was used for the assessment of the effect of 'immune' plasma in the anti-malarial drug sensitivity assays. We found that plasma containing anti-malarial antibodies significantly increased the apparent susceptibility of $P$. falciparum to quinine and also had a borderline effect on artesunate. These effects were greater at low drug concentrations distorting the normal sigmoid shape of the concentration-effect relationship. $\mathrm{IC}_{50}$ values for quinine were markedly altered whereas $\mathrm{IC}_{90}$ values were not affected significantly. As $\mathrm{IC}_{50}$ values are usually reported, these 


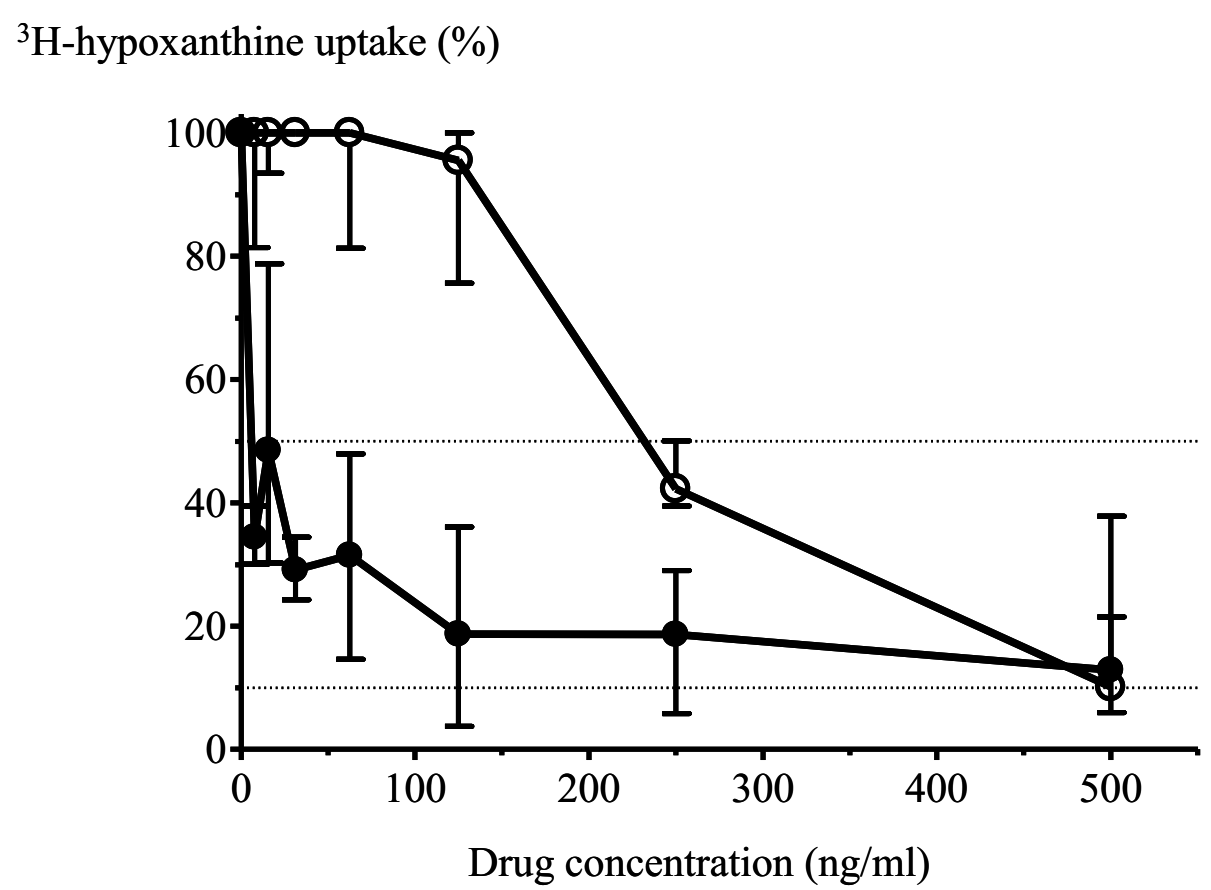

$2 \mathrm{~A}$

${ }^{3} \mathrm{H}$-hypoxanthine uptake $(\%)$

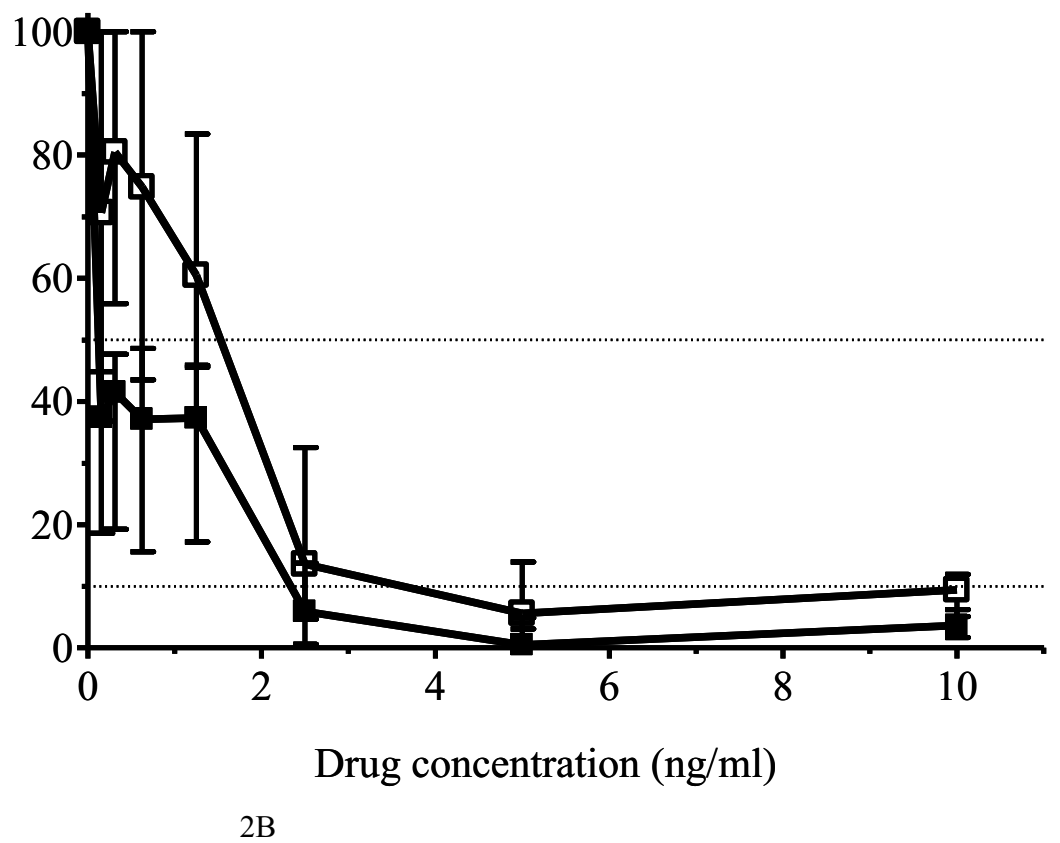

Figure 2 The dose-response curve of $P$. falciparum anti-malarial drug susceptibility. Parasites were incubated with A) quinine without 'immune' plasma (white circle) and quinine with 10\% 'immune' plasma (black circle) (range: 7.80-500 ng/ml); and B) artesunate without 'immune' plasma (white square) and artesunate with 10\% 'immune' plasma (black square) (range: $0.16-10 \mathrm{ng} / \mathrm{ml}$ ). The percentage of ${ }^{3} \mathrm{H}$ hypoxanthine uptake was plotted against drug concentrations. The dotted lines represent $50 \%$ and $90 \%$ inhibition. Data are shown as the median values and interquartile ranges from 4 experiments. 


\section{Difference in ${ }^{3} \mathrm{H}$-hypoxanthine uptake (\%)}

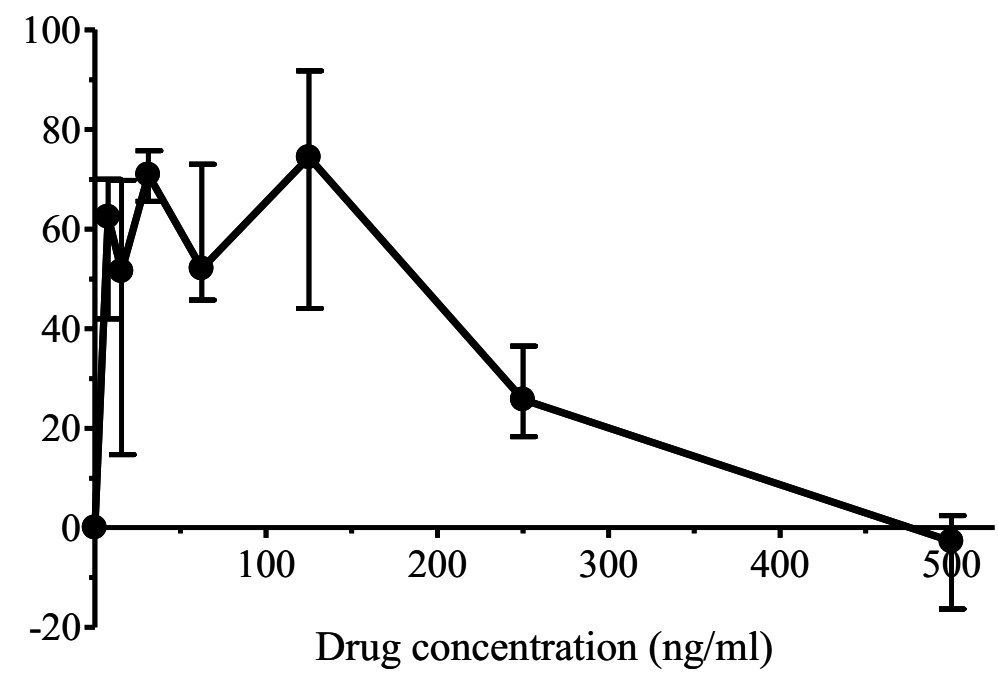

$3 \mathrm{~A}$

\section{Difference in ${ }^{3} \mathrm{H}$-hypoxanthine uptake (\%)}

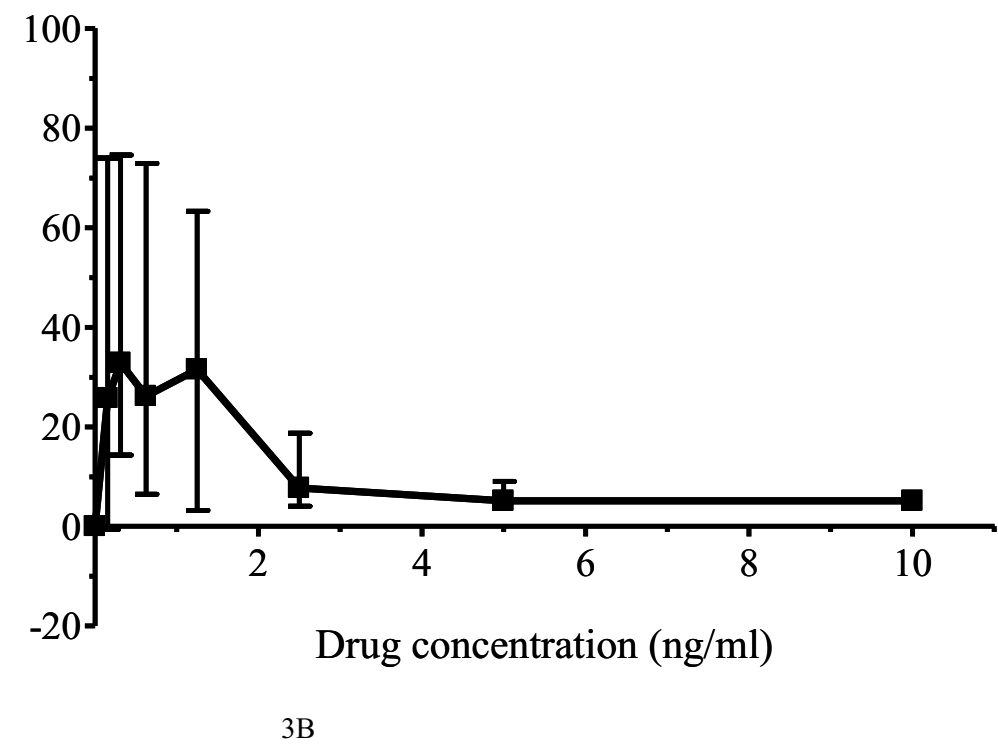

Figure 3 Modulating effects of 'immune' plasma containing anti-malarial antibodies on in vitro P. falciparum anti-malarial drug susceptibility. The magnitude of the effect of 'immune' plasma on the susceptibility to $\mathbf{A}$ ) quinine (black circle) and $\mathbf{B}$ ) artesunate (black square) expressed as the percentage of ${ }^{3} \mathrm{H}$-hypoxanthine uptake without 'immune' plasma subtracted to that of drug combined with $10 \%$ 'immune' plasma containing anti-malarial antibodies. Data are shown as the median values and interquartile ranges from 4 experiments.

findings suggest that improved malaria control with consequent population reduction in malaria antibody titers might lead to a rise in $\mathrm{IC}_{50}$ values of fresh isolates. This could be mistaken as indicating increasing resistance. The effects of 'immune' plasma on quinine $\mathrm{IC}_{50}$ values were much greater than on artesunate. The stagespecificity of the effect of anti-malarial antibodies might explain this difference. If antibodies recognize antigenic determinants on more mature trophozoites and therefore act predominantly at that stage, then they may have a 
greater effect in synergistically with drugs, which act only at this stage. Quinine acts predominantly on mature parasites whereas artesunate has a broad stage-specificity and acts on both young and mature stages. Future studies to characterize and assess the factors in 'immune' plasma which interfere specifically with parasite growth are required.

\section{Conclusions}

'Immune' plasma containing anti-malarial antibodies inhibits intraerythrocytic development of $P$. falciparum as well as parasite multiplication in an in vitro growth system. 'Immune' plasma increased in vitrosusceptibility to quinine and also had a borderline effect on artesunate susceptibility. Effects were greater at low drug concentrations, so the $\mathrm{IC}_{50}$ was affected much more than the $\mathrm{IC}_{90}$ estimates.

\begin{abstract}
Acknowledgements
We thank Miss Juntima Sritabal, Miss Patthamon Tharaphan, Mr. Sompob Saralamba, and staff of the Mahidol-Oxford Tropical Medicine Research Unit (MORU), Faculty of Tropical Medicine, Mahidol University, and Department of Parasitology, Phramongkutklao College of Medicine, Thailand, for their technical support, suggestions and helpful discussions. Special thanks for Miss Naruemon Sitthichot for her kind support in performing the isotopic assay. Preeyaporn Monatrakul was supported by Thailand Research Fund through the Royal Golden Jubilee Ph.D. Programme (Grant No. PHD/0219/ 2547). This work was supported by Thailand Research Fund, Faculty of Tropical Medicine, Mahidol University and was part of the Wellcome Trust Mahidol University-Oxford Tropical Medicine Research Programme funded by the Welcome Trust of Great Britain.
\end{abstract}

\section{Author details}

${ }^{1}$ Department of Clinical Tropical Medicine, Faculty of Tropical Medicine, Mahidol University, 420/6 Rajvithi, Bangkok, Thailand 10400. ²Department of Parasitology, Phramongkutklao College of Medicine, Bangkok, Thailand. ${ }^{3}$ Mahidol-Oxford Tropical Medicine Research Unit, Faculty of Tropical Medicine, Mahidol University, Bangkok, Thailand. ${ }^{4}$ Critical Care Research Unit, Department of Clinical Tropical Medicine, Mahidol University, Bangkok, Thailand. ${ }^{5}$ Department of Pathobiology, Faculty of Science, Mahidol University, Bangkok, Thailand.

\section{Authors' contributions}

PM: carried out the experimental work, data analysis, and wrote the first draft of the manuscript. MM: gave technical support and helped preparing the manuscript. RU: provided laboratory support and helped in the revision of the manuscript. SK and PW: contributed to patient recruitment and patient care as well as collection of blood samples. AMD: helped in data analysis and writing of the manuscript. NJW: helped design the experiments, revise the manuscript, and analyse the data. KC: helped design the experiments, gave technical support, supervision, and helped in data analysis and writing of the manuscript. All authors have been seen and approved this manuscript.

\section{Competing interests}

The authors declare that they have no competing interests.

Received: 14 July 2010 Accepted: 16 November 2010 Published: 16 November 2010

\section{References}

1. Yorke W, Macfie JWS: Observations on malaria made during treatment of general paralysis. Trans R Soc Trop Med Hyg 1924, 18:13-33.
2. Tin F, Nyunt-Hlaing : Comparative drug trial of a sulfadoxine/ pyrimethamine and a sulfalene/pyrimethamine combination against Plasmodium falciparum infections in semi-immune populations of Burma. Southeast Asian J Trop Med Public Health 1984, 15:238-248.

3. Draper CC, Brubaker G, Geser A, Kilimali VA, Wernsdorfer WH: Serial studies on the evolution of chloroquine resistance in an area of East Africa receiving intermittent malaria chemosuppression. Bull World Health Organ 1985, 63:109-118.

4. Smithuis FM, Monti F, Grundl M, Oo AZ, Kyaw TT, Phe O, White NJ: Plasmodium falciparum: sensitivity in vivo to chloroquine, pyrimethamine/sulfadoxine and mefloquine in western Myanmar. Trans R Soc Trop Med Hyg 1997, 91:468-472.

5. Aubouy A, Migot-Nabias F, Deloron P: Correlations between treatment outcome and both anti-MSP1 ${ }_{19}$ antibody response and erythrocyterelated genetic factors in Plasmodium falciparum malaria. Infect Genet Evol 2007, 7:147-154

6. Carrara VI, Zwang J, Ashley EA, Price RN, Stepniewska K, Barends M, Brockman A, Anderson T, McGready R, Phaiphun L, Proux S, van Vugt M, Hutagalung R, Lwin KM, Phyo AP, Preechapornkul P, Imwong M, Pukrittayakamee S, Singhasivanon P, White NJ, Nosten F: Changes in the treatment responses to artesunate-mefloquine on the northwestern border of Thailand during 13 years of continuous deployment. PLOS One 2009, 4:e4551.

7. Cranmer SL, Magowan C, Liang J, Coppel RL, Cooke BM: An alternative to serum for cultivation of Plasmodium falciparum in vitro. Trans $R$ Soc Trop Med Hyg 1997, 61:363-365.

8. Lambros C, Vandenberg J: Synchronization of Plasmodium falciparum erythrocytic stages in culture. J Parasitol 1979, 65:418-420.

9. Perlmann H, Berzins K, Wahlgren M, Carlsson J, Björkman A, Patarroyo ME, Perlmann P: Antibodies in malarial sera to parasite antigens in the membrane of erythrocytes infected with early stages of Plasmodium falciparum. J Exp Med 1984, 159:1686-1704.

10. Silamut K, Phu NH, Whitty C, Turner GD, Louwrier K, Mai NT, Simpson JA, Hien TT, White NJ: A quantitative analysis of the microvascular sequestration of malaria parasites in the human brain. Am J Pathol 1999, 155:395-410.

11. Webster HK, Boudreau EF, Pavanand K, Yongvanitchit K, Pang LW: Antimalarial drug susceptibility testing of Plasmodium falciparum in Thailand using a microdilution radioisotope method. Am J Trop Med Hyg 1985, 34:228-235.

12. Guevara Patino JA, Holder AA, McBride JS, Blackman MJ: Antibodies that inhibit malaria merozoite surface protein-1 processing and erythrocyte invasion are blocked by naturally acquired human antibodies. J Exp Med 1997, 186:1689-1699.

13. Sim BKL: Delineation of functional regions on Plasmodium falciparum EBA-175 by antibodies eluted from immune complexes. Mol Biochem Parasitol 1998, 95:183-192.

14. Ray P, Sahoo N, Singh B, Kironde FAS: Serum antibody immunoglobulin G of mice convalescent from Plasmodium yoelii infection inhibits growth of Plasmodium falciparum in vitro: blood stage antigens of $P$. falciparum involved in interspecies cross-reactive inhibition of parasite growth. Infect Immun 1994, 62:2354-2361.

15. Berzins K, Perlmann $H$, Wåhlin $B$, Carlsson J, Wahlgren $M$, Udomsangpetch R, Björkman A, Patarroyo ME, Perlmann P: Rabbit and human antibodies to a repeated amino acid sequence of a Plasmodium falciparum antigen, $\mathrm{Pf} 155$, react with the native protein and inhibit merozoite invasion. Proc Natl Acad Sci USA 1986, 83:1065-1069.

16. Wahlin B, Sjölander A, Ahlborg N, Udomsangpetch R, Scherf A, Mattei $D$ Berzins K, Perlmann P: Involvement of Pf155/RESA and cross-reactive antigens in Plasmodium falciparum merozoite invasion in vitro. Infect Immun 1992, 60:443-449.

17. Siddique AB, Ahlborg N, Wahlin Flyg B, Perlmann P, Berzins K: Antibodies to sequences in a non-repeat region of Plasmodium falciparum antigen Pf155/RESA inhibit either cytoadherence or parasite growth in vitro. Parasitology 1998, 117:209-216.

18. Mayxay M, Chotivanich K, Pukrittayakamee S, Newton P, Looareesuwan S, White NJ: Contribution of humoral immunity to the therapeutic response in falciparum malaria. Am J Trop Med Hyg 2001, 65:918-923. 
19. Marsh K, Howard RJ: Antigens induced on erythrocytes by P. falciparum: expression of diverse and conserved determinants. Science 1986, 231:150-153.

20. Migot-Nabias F, Luty AJ, Ringwald P, Vaillant M, Dubois B, Renaut A, Mayombo RJ, Minh TN, Fievet N, Mbessi JR, Millet P, Deloron P: Immune responses against Plasmodium falciparum asexual blood-stage antigens and disease susceptibility in Gabonese and Cameroonian children. Am J Trop Med Hyg 1999, 61:488-494.

21. Friedman MJ: Control of malaria virulence by alpha 1-acid glycoprotein (orosomucoid), an acute-phase (inflammatory) reactant. Proc Natl Acad Sci USA 1983, 80:5421-5424.

22. Nussler A, Pied S, Pontet M, Miltgen F, Renia L, Gentilini M, Mazier D: Inflammatory status and preerythrocytic stages of malaria: Role of the Creactive protein. Exp Parasitol 1991, 72:1-7.

23. Janeway CA, Travers P, Walport M, Shlomchik M: The complement system and innate immunity. Immunobiology: The Immune System in Health and Disease. 6 edition. New York: Garland Science; 2005, 55-75.

24. Soltis RD, Hasz D, Morris MJ, Wilson ID: The effect of heat inactivation of serum on aggregation of immunoglobulins. Immunology 1979, 36:37-45.

doi:10.1186/1475-2875-9-326

Cite this article as: Monatrakul et al:: Modulating effects of plasma containing anti-malarial antibodies on in vitro anti-malarial drug susceptibility in Plasmodium falciparum. Malaria Journal 2010 9:326.

\section{Submit your next manuscript to BioMed Central} and take full advantage of:

- Convenient online submission

- Thorough peer review

- No space constraints or color figure charges

- Immediate publication on acceptance

- Inclusion in PubMed, CAS, Scopus and Google Scholar

- Research which is freely available for redistribution

Submit your manuscript at www.biomedcentral.com/submit 